Revista Iberoamericana, Vol. LXXVII, Núms. 236-237, Julio-Diciembre 2011, 975-987

\title{
IMAGEN, DESEO Y PALABRA EN EL AMOR ES UNA DROGA DURA DE CRISTINA PERI ROSSI
}

\author{
POR \\ Parizad DeJBord-SAWAN \\ The University of Akron
}

El amor es una droga dura es la última novela de Cristina Peri Rossi, publicada el mismo año que su libro de poemas Las musas inquietantes (1999). A pesar de que pertenecen a géneros literarios diferentes, ambos están informados por la inclusión de pinturas, esculturas, dibujos y fotografías a sus páginas. En Las musas inquietantes las formas de arte son canónicas -cincuenta pinturas y una escultura- mientras que en El amor es una droga dura se textualizan tanto las expresiones canónicas del arte -siete pinturas-como las no canónicas-fotografías-. Además, en la novela el discurso ekfrástico no surge solamente para evocar obras visuales tradicionales o marginales, sino que el texto literario también inventa un objeto de belleza, evoca la imagen de una mujer ficticia, Nora, e inscribe el efecto que su contemplación, junto con la contemplación de sus fotografías, produce en el protagonista-fotógrafo. ${ }^{1}$

El objetivo de este trabajo es explorar la función de la inscripción de las imágenes de Courbet, Freidrich, Ingres, Lempicka, López y Magritte, junto con las imágenes de la protagonista, Nora, en la novela. El propósito es indicar las correspondencias entre esas imágenes, la mirada y el deseo del protagonista con el objetivo de señalar el valor que el arte y el fetiche asumen para la mirada del protagonista masculino durante el transcurso de la novela.

Con la publicación de Las musas inquietantes y El amor es una droga dura podemos aseverar que 1999 representa un momento muy significativo en la textualización del creciente interés de la autora en las correspondencias entre la mirada, la imagen y el deseo; preocupación que venía ya anunciándose en la obra de esta escritora desde múltiples perspectivas. Más de una década antes, su interés en la pasión amorosa y la contemplación compulsiva del objeto de deseo erótico se manifiesta en su novela Solitario

1 Para definiciones y discusiones críticas y teóricas sobre el concepto de ekfrasis consultar el primer capítulo de Getting the Picture. The Ekphrastic Principle in Twentieth-Century Spanish Poetry de Margaret H. Persin y Art Inscribed: Essays on Ekphrasis in Spanish Golden Age Poetry de Emilie L. Bergmann. Aquí mi uso de "ekfrasis" se basa en la definición más amplia de arte proporcionada por Persin en su estudio (18). 
de amor (1988). En este texto, el narrador y protagonista masculino obsesivamente contempla a su fetiche, la encarnación o proyección corporal de su deseo, en la figura de su amada Aída. El protagonista anónimo no actúa, no tiene pasado ni futuro. Este mantiene un existir larvario, una existencia hipnótica de dependencia que gira únicamente en torno a la contemplación estática de ella y de los signos y símbolos que la convocan. La articulación de esta compulsión se da dentro del marco teórico del psicoanálisis lacaniano y kristeviano, de manera que la dependencia del personaje se proyecta en el deseo de recuperar la ausencia y la unidad irrecuperable con la madre.

En 1991, Peri Rossi retoma el tema desde una nueva perspectiva: la del ensayo. En Fantasías eróticas Peri Rossi se dirige al tema del deseo por medio de la discusión sobre las fantasías sexuales y el erotismo. En este texto la autora parte de la premisa, explícitamente postulada, de que el arte es la fuente necesaria para todo acercamiento a la temática del deseo:

Es justamente en el arte donde hay que buscar el erotismo, porque él se ocupa de las fantasías, de los deseos, de lo innombrable, porque el arte no imita a la realidad, sino que la transmuta, la transforma, la hace desagradable o apetecible, la cubre de emociones. En el arte, la realidad adquiere su más preciosa condición: La ambigüedad y la pluralidad. (Fantasías eróticas 44)

Es desde el terreno de la imaginación y por medio de la mirada donde surgen las imágenes que convierten a un cuerpo en objeto de deseo. Es mediante el símbolo y la metáfora que se intenta nombrar lo que elude ser nombrado e inscribirlo o plasmarlo en el texto:

Lo imaginario, que se constituye como fabulación y representación, es decir como símbolo y metáfora, intenta nombrar lo innombrable (el cuerpo del deseo) y transferir sus emociones al lenguaje, al poema, al cuadro, al cine. (Fantasías eróticas 46)

Peri Rossi señala que el mecanismo simbólico de la traslación ha generado una cadena de significantes que constituyen, tanto en el arte como en la literatura, un repertorio de objetos analógicos a la sexualidad masculina -la corbata, el sombrero, la estilográfica, la motocicleta, el lápiz, la serpiente, el obelisco, el misil y el cigarrillo- o a la femenina -la rosa de innumerables pétalos, la araña, el melocotón de dos mitades, el higo meloso y el mar-. En Solitario de amor esta simbología, que surge de la contemplación del objeto de deseo erótico, se erige sobre un sistema de significantes esencialistas y fálicos construidos por el contemplador masculino que identifica a la mujer con la casa y la cerradura, y al hombre con la llave:

El sexo de Aída es una cerradura. Intervengo en él como el extranjero dotado de una llave que abre la puerta para explorar la casa extraña [...] [M]i cuerpo es diferente al

Revista Iberoamericana, Vol. LXXVII, Núms. 236-237, Julio-Diciembre 2011, 975-987 
suyo y mi sexo es una llave, no una casa [...] Otra es la tradición de las llaves, otra es la tradición de las casas [...] Llaves, casas. (Solitario 35)

Once años más tarde, en El amor es una droga dura, el personaje masculino es prácticamente una re-encarnación del protagonista consumido por el deseo en Solitario de amor, con el agregado de que ahora posee una historia propia que compartir antes del enamoramiento. Javier es un atractivo fotógrafo publicitario casado de cuarenta y ocho años que en el pasado había sido corresponsal de guerra en Ruanda, Nicaragua y Afganistán, y que se dedica, en el presente, exclusivamente a fotografiar coches y a modelos a quienes seduce de forma desvergonzada. La acción comienza cuando, poco después de sufrir una hipertrofia cardiaca, es llevado a la ciudad donde también es sometido a una desintoxicación por su adicción intensa al tabaco, al alcohol y a la cocaína. Poco después ve a Nora, una joven modelo, en la calle y es sacudido convulsivamente por su imagen:

Había caminado unos cuantos metros, cuando de pronto, vio una imagen que lo deslumbró. Sintió una especie de conmoción, una fuerte sacudida externa, pero diferente a cualquier cosa que hubiera sentido antes. No tenía que ver sólo con el cuerpo [...] La conmoción era de otra índole, similar a una revelación. Y había accedido a través de los sentidos. (Amor 20-21)

Como anuncia el título de la novela, el devenir del personaje será uno consumido por la adicción de su deseo por Nora. Al igual que el personaje en Solitario de amor, la contemplación del fetiche convocará una simbología esencialista fálica con el agregado de que Javier ya ha articulado una relación fálica con su profesión -la fotografía- y con el instrumento de su profesión -la cámara. La “penetración” deseada, la seducción de una Nora elusiva se da por medio del ojo de la cámara que es representado en el texto mediante el símbolo del falo: ${ }^{2}$

[... en él la mirada era un acto de aprehensión, una forma de penetrar. [...] La cámara era como un falo permanentemente erecto, con el cual intentaba penetrar la realidad, dominarla, conquistarla y retenerla. (Amor 21)

Margarita Saona en su artículo "La masculinidad en crisis: El amor es una droga dura” señala, muy acertadamente, que la novela se estructura en torno al carácter inicialmente ${ }^{3}$ fálico de su protagonista cuya masculinidad se articula por medio del

2 Su sicoanalista, Francisco, le hace notar precisamente esa simbología esencialista: "No tengo que explicarte, querido, la simbología fálica de tu cámara...” (El amor es una droga dura 75)

3 Uso la palabra "inicialmente" de forma deliberada porque la tesis de Saona es precisamente que esta identidad masculina fálica y esencialista es finalmente deconstruida cuando Javier renuncia “a su virilidad

Revista Iberoamericana, Vol. LXXVII, Núms. 236-237, Julio-Diciembre 2011, 975-987 ISSN 0034-9631 (Impreso) 
deseo de competitividad y posesión que, en el contexto de la novela, caracteriza la vida contemporánea en las grandes ciudades.

Sin embargo, a diferencia de las conquistas o posesiones sexuales anteriores que eran rápidas, pasajeras y carentes de carga emotiva, la contemplación súbita de Nora hace que el protagonista se sienta colmado por la emoción:

De todos modos para disimular su turbación desvió la mirada, pero enseguida comprendió que se trataba de una maniobra inútil [...] Comenzó a transpirar y contuvo un arrebato de ansiedad que podía convertirse en pánico. (Amor 22-23)

Peri Rossi explica en Fantasías eróticas que cuando la libido no se proyecta en un objeto particular el deseo amoroso no se distingue de las otras funciones corporales. Al colocar nuestra libido en un objeto lo separamos de nosotros mismos, por lo cual el poseerlo se vuelve imposible (Fantasías eróticas 43-48). En la novela, a la turbación experimentada por Javier ante la visión de Nora se le da nombre: se le llama el "síndrome de Stendhal”. ${ }^{4}$ Javier lee por primera vez sobre el fenómeno en un diario donde una periodista y psiquiatra italiana, Sylvia Magherini, citada al comienzo de la novela, lo había estudiado en turistas de nacionalidades diferentes que experimentaban trastornos y palpitaciones al estar expuestos, por un tiempo prolongado, a la belleza de las obras de arte en museos. ${ }^{5}$ Por lo tanto, la reacción psíquica y sensorial que experimenta Javier ante la imagen de Nora puede ser entendida dentro del marco de aquéllas experimentadas por los pacientes de Magherini al estar expuestos, en los museos, a una sobredosis o acumulación de belleza. Desde esta posición, el cuerpo y la imagen de Nora son recreados en el texto análogamente como otro objeto de arte. ${ }^{6}$

Rocco Mangieri, en su artículo sobre la película deArgento "The Stendhal Syndrome”, explora el tema de la belleza y la percepción corporal del sujeto mirante desde una teórica óptica que aúna la semiosis (Greimas), el psicoanálisis (Freud y Lacan) y la biología (Tom y Zeeman). Desde su perspectiva existe una relación económica particular

entendida como el reino del falo” (6). En su artículo, Saona muestra de manera muy convincente cómo las diferentes experiencias de Javier, en el transcurso de la novela, le revelan el carácter fantasmático de la ficción dominante que ubica el falo y la penetración en el centro de las fantasías de plenitud del sujeto masculino.

4 El síndrome lleva el nombre del escritor francés que experimentó similares trastornos cuando visitó la basílica de La Santa Croce. Asimismo, según la novela, Marcel Proust lo experimentó en 1921 en el Jeu de Paume ante el cuadro "Vista de Delft" del pintor flamenco Vermeer.

5 The Stendhal Syndrome también es el título de una película italiana de Dario Argento (1996) y de una obra doble de teatro de 2004 por Terrence McNally, The Stendhal Syndrome. Full Frontal Nudity and Prelude \& Liebestod.

${ }_{6}$ Esa equivalencia Nora-objeto de arte es textualizada además discursivamente por el propio Javier quien decide no distraerse por la conversación de ella para dedicarse de lleno en su contemplación: "Era el precio de la contemplación de la belleza. ¿Acaso los museos no cobraban la entrada?” (38)

Revista Iberoamericana, Vol. LXXVII, Núms. 236-237, Julio-Diciembre 2011, 975-987 ISSN 0034-9631 (Impreso) 
que se establece, bajo este síndrome, entre "el sujeto mirante” y "la obra de arte que es mirada”. La estructura del funcionamiento del síndrome es tal que se produce un desplazamiento inusual: una inversión entre las identidades del sujeto y del objeto. Es decir, el sujeto primario se convierte en objeto de la mirada de la obra de arte hasta tal grado que la obra de arte siniestramente -en términos freudianos- captura y atrapa al que mira. Efectivamente, Javier pierde su agencia ante la imagen al sentirse capturado por “el poderoso imán colocado al azar en su camino, pero cuya fuerza era irresistible” (Amor 22). Su intento de escapar la captura mediante una desviación de la mirada falla porque la imagen ya se había quedado fijada en su retina: "había quedado prisionero, encerrado en su propia trampa. Se sintió en peligro” (Amor 23).

Una lectura de los testimonios de los participantes en el estudio de Graziella Magherini -siquiatra seguidora de Lacan y Freud- indica que los efectos del síndrome son análogos a aquéllos experimentados por Javier: elevación de ritmo cardíaco, malestar, desequilibrio, parálisis y sensación de captura por el objeto de arte. Curiosamente, durante la experiencia escópica el sujeto padeciente experimenta dos reacciones contradictorias y que, sin embargo, ocurren simultáneamente: la adherencia a la imagen a la par de una aversión hacia la misma:

[...] se trata de fenómenos visuales y corporales en los cuales el punto de partida (la punta del iceberg semiótico) es la aparición, a la vez deseada e inesperada, de algo que perturba un sistema de equilibrio anterior y que lo somete progresivamente a un entorno que entremezcla la atracción y el rechazo, el deseo y el temor, el desapego y la adhesión, la afirmación y la interrogación. (Mangieri)

Esas tensiones opuestas, a las cuales hace referencia Mangieri, están claramente presentes en el instante de parálisis experimentado por Javier, quien se siente a la vez atraído por ella y ansioso por huir. ${ }^{7}$ Desde la perspectiva de Mangieri, la causa de esta “captura icónica” no puede explicarse únicamente por la belleza predadora exteriorizada del objeto que captura, sino que debe encontrar su explicación en el plano sicoanalítico. En la novela, el propio Javier intuye que hay algo más, innombrable, detrás de esta experiencia de atropamiento pulsional en la red escópica; algo más allá de la belleza en la superficie de la imagen:

No podía tratarse sólo de belleza. Aunque la mujer a la que estaba mirando, contemplando, extasiado, fascinado, hipnotizado, era indiscutiblemente hermosa, en sus años de profesional de fotografía se había encontrado muchísimas veces ante mujeres hermosas

\footnotetext{
7 "Porque nunca había experimentado antes esa sensación de turbación, de desconcierto, esas ganas contradictorias de huir y acercarse, de hablar con ella, de abordarla y esperar, confusamente que ella hiciera algo por él” (Amor 25).

Revista Iberoamericana, Vol. LXXVII, Núms. 236-237, Julio-Diciembre 2011, 975-987
ISSN 2154-4794 (Electrónico)
} 
[...] Había visto tantas mujeres hermosas -por su profesión- que hasta cierto punto se volvió insensible [...] (Amor 22)

Ese desasosiego o estado de turbación es reconocido inmediatamente por Javier, puesto que él mismo lo experimentó la primera vez, a los seis años, cuando la visión de la bella cabellera castaña de una niña lo hizo caer en un estado de delirio y éxtasis. Esa experiencia escópica de fetichsimo ${ }^{8}$ para él no fue fijada en su memoria por el lenguaje codificado -"no tuvo palabras para decírselo a si mismo" (Amor 78)- sino que dejó una impresión indeleble en su memoria. ${ }^{9}$

A pesar del artículo sobre la siquiatra Magherini, quien le da nombre y etiqueta al fenómeno en 1979, y a pesar de que su sicoanalista Francisco insista en que su fascinación por Nora se trata del tal llamado síndrome, ${ }^{10}$ Javier, desde el marco de una experiencia oscuramente pasada pero retornante, intuye que se trata de otra cosa. La constatación de que el "atrapamiento" al cual ha sido sometido no se explica, como falsamente le ha indicado Francisco, únicamente desde la belleza física de Nora; la conclusión a la que llega el propio Javier es de que el fenómeno tampoco puede explicarse desde las características personales de ella ${ }^{11}$ lo impulsa a la indagación y pone en marcha en él un proceso de concienciación. Es decir, que se da en él una voluntad de desentrañar, para bien o para mal, el misterio de su seducción; de conocer y discernir la causa del deseo a pesar del terror y la revulsión inexplicables que experimenta en la captura escópica:

En cuanto a él, Javier, cuando veía a Nora, sentía deseos de vomitar como si su belleza tuviera un revulsivo insoportable de digerir. Pero él era un valiente: no huía. En realidad, su desafío mayor era atraparla, analizar, descubrir la belleza. Poseerla para dominarla, y de ese modo, desentrañarla. (Amor 82-83)

Desde el marco teórico de Freud, se trata, para Javier, de una imagen que tiene la capacidad de convocar, contradictoriamente, lo familiar -la imagen reconocible de una mujer-y lo siniestro-aquello “insoportablemente indigerible”-de lo cual busca escapar. Esa capacidad de convocatoria de una imagen que marca el paso de lo familiar a lo no familiar puede y debe ser entendido en el contexto de la teoría de lo "ominoso" de

8 Peri Rossi explora en su libro de ensayos los valores de fetiche que adquieren la cabeza y el cabello para el enamorado desde la antigüedad (Fantasías eróticas 118-19).

9 “[...] la experimentó a una edad en que carecía del lenguaje adecuado para expresarla, pero dejó una huella, un surco en su cerebro que luego reaparecería, porque formaba parte de su inconsciente” (78).

10 "Has contraído el 'síndrome de Stendhal' llamado también 'la enfermedad de los museos'. Son los trastornos psicosomáticos que sufren ciertos individuos ante la contemplación de la belleza. Teniendo en cuenta que eres fotógrafo y de personalidad adictiva, no es nada raro que te ocurra a ti” (73).

11 “Cómo era posible estar tan enamorado de ella y, sin embargo, no sentir ningún interés por su vida?” (Amor 39).

$\begin{array}{lllll}\text { ISSN 0034-9631 (Impreso) } & \text { ISSN 2154-4794 (Electrónico) }\end{array}$ 
Freud y sus postulados sobre el "heimlich" y el "unheimlich": "Heimlich thus becomes increasingly ambivalent, until it finally merges with its antonym unheimleich. The uncanny (das Unheimliche, 'the unhomely') is in some ways a species of the familiar (das Heimliche, 'the homely')” (Freud 134). Inscrita en esta búsqueda, donde el sujeto pugna por desentrañar aquello que no comprende de sí mismo, se está textualizando la fragmentación de un yo, escindido de sí mismo, en su captura paradójica por la figura escópica de Nora.

Esta fragmentación se manifiesta también en la doble voz de Javier. En oposición a la fatigante voz interior, personal y solitaria que emerge durante las frecuentes ausencias de Nora, existe también la voz "normal” exterior, más plana, de función comunicativa que activa con el resto del mundo y con su esposa Gema. Esa voz interior que intenta esclarecer el sentido del deseo, estando el fetiche ausente, se aúna con un desplazamiento espacial hacia atrás que escarba en el pasado oscuro y acuático de lo reprimido ocultado por un pacto subliminal con el olvido:

Con Gema, la comunicación real era satisfactoria: quizás por eso, la voz no existía. Pero tampoco existía esta apasionada rememoración de su vida, este rescate de su pasado que le permitía vivir como actuales hechos y sentimientos que había olvidado. Había más comunicación, pero era plana, no surgía de la profundidad acuática de su pasado. Porque todo pasado era agua: aguas estancadas, aguas oscuras, aguas cenagosas, aguas convulsas. Tenia que encontrar algún recurso para dejar de oír la voz. Temía volverse loco. (Amor 68-69)

En el capítulo “Una inmersión en la fantasías marinas” Peri Rossi examina el valor polivalente del significado simbólico y cultural del agua (Fantasías 57-67). La autora destaca su naturaleza líquida y cambiante, su fuerza y su mansedumbre, el carácter “insondable de sus profundidades” e indica que "Para Freud el mar es la representación del inconsciente” mientras que para descifradores de símbolos anteriores a él "representa las pulsiones más hondas y oscuras de nuestro ser”. Si consideramos la cita anterior de la novela, entendemos los sentidos múltiples del signo "agua” que señala Peri Rossi. Aquí, la referencia a aguas “estancadas”, “oscuras”, “cenagosas” y “convulsas” apunta a las pulsaciones más escondidas y violentas que retornan de un pasado reprimido y que emergen, con significación velada, como efecto de la imagen de Nora. Estas pulsaciones no afloran únicamente como reacción a la presencia de Nora, sino que también son generadas por la contemplación de otras imágenes: de objetos de arte.

El primer cuadro que se textualiza en la novela es, precisamente, uno en el que vuelve a evocarse la oscuridad inquietante del agua. Se trata de un naufragio del pintor romántico alemán Caspar David Friedrich (1774-1840) que Javier contempla en el museo de Charlottemburg en Berlín. Aquí, el discurso ekfrástico no se detiene para describir en detalle los aspectos minuciosos del cuadro innombrado de Freidrich. Por lo tanto, se

\footnotetext{
Revista Iberoamericana, Vol. LXXVII, Núms. 236-237, Julio-Diciembre 2011, $975-987$
ISSN 0034-9631 (Impreso)
} 
hace en definitiva casi imposible saber si se trata del bien conocido: "El océano glacial o el naufragio de la Esperanza” (1824), incluido también en la colección Las musas inquietantes. De hecho, en su libro de poemas Peri Rossi réune cinco imágenes, en los desplegables ubicados al final de la colección, que posiblemente puedan relacionarse con el naufragio al cual se alude en la novela. Hay dos pinturas de Friedrich: "El viajero sobre el mar de nubes" (1818) y "El océano glacial o el naufragio de la Esperanza”, y dos cuadros del romántico inglés Joseph Mallard William Turner (1775-1851): "Naufragio" (1805) y “La mañana después del diluvio". ${ }^{12}$ Los cuatro poemas correspondientes entran en diálogo ekfrástico con los cuadros -“El viajero sobre el mar de nubes” (31), "El océano glacial” (33), “Naufragio”(39) y “La mañana después del Diluvio”(41). Dichos poemas comunican una visión solitaria del hombre (o "solitario mástil en la densidad"), del bajel que "agoniza," del "esquife/sola humanidad" en una tormenta o "torbellino vertiginoso de aguas marinas" y expresan la soledad existencial a la vez que anuncian la muerte. Similarmente, en el cuadro que contempla Javier en el museo, el agua, como motivo plástico, provoca en él una angustia existencial:

No había nadie, esa tarde, en el pequeño museo, y depronto, descubrió un óleo enteramente negro, con la negrura de las pesadillas marinas, la negrura de los mensajes que vienen del inconsciente. Javier se sintió inquieto. Pensó que el sudor se debía a la calefacción, pero enseguida comprendió que no era eso: había mirado el naufragio de Caspar David Friedrich como se mira una pesadilla familiar, algo que se ha visto ya, en otra parte, y se creía olvidado. La plenitud del negro lo atraía hacia el abismo [...] (Amor 81)

Como en el caso de su captura por la imagen magnética de Nora, aquí de nuevo se inscriben las mismas tensiones polarizadas de atracción y repulsión. La negrura marina del óleo y la oscuridad de las profundidades lo angustian y lo descomponen física y síquicamente a la vez que lo atraen inevitablemente al negro abismo. Javier se halla atrapado en la mirada escópica del cuadro de Friedrich de la misma manera que Ana, la protagonista de la película de Argento, se halla enredada en la arquitectura del cuadro "Paisaje con la caída de Ícaro" (1554-1555), del pintor flamenco renacentista Pieter Brueghel el Viejo (1525-1569). ${ }^{13}$ Como señala Mangieri en su esclarecedor estudio durante la experiencia escópica: "el sujeto es conducido como en un viaje virtual hacia el interior del espacio de la pintura.” Surge de nuevo, en esta descripción del cuadro

${ }_{12}$ En otro momento de la novela el narrador hará una referencia general a Turner en el contexto del terror que le producen sus imágenes del agua, al igual que las de Friedrich: "Pero había un mar oscuro y nocturno, denso, impenetrable (el mar de Caspar David Friedrich o de William Turner), que era hondo, peligroso, tanático" (Amor 182).

13 Curiosamente, Peri Rossi también incluye este cuadro de Brueghel en su libro de poemas Las musas inquietantes. El poema que le corresponde se llama "El Nuevo Mundo" (29).

Revista Iberoamericana, Vol. LXXVII, Núms. 236-237, Julio-Diciembre 2011, 975-987 ISSN 0034-9631 (Impreso) 
de Friedrich, la referencia a lo terrorífico junto a lo familiar. Una vez más, como indica Freud, "heimlich” y "unheimlich” se encuentran conjugados mediante el retorno de lo reprimido que aquí emerge para Javier por medio del arte:

[...] it follows that among those things that are felt to be frightening there must be one group in which it can be shown that the frightening element is something that has been repressed and now returns. This species of the frightening would then consititute the uncanny, and it would be inmaterial whether it was itself originally frightening or rose from another affect [...] for this uncanny element is actually nothing new or strange, but something that was long familiar to the psyche and was estranged from it only through being repressed. (Freud 147-48)

Terrorífico y sin embargo también familiar, puesto que aquello olvidado vuelve obsesiva e irremediablemente, a modo de revelación, también en los sueños. Javier, en su viaje hacia el esclarecimiento de la causa del deseo, llega a constatar "que no era en el objeto donde había que buscar la causa del deseo, sino en el deseante” (Amor 21).

Y sin embargo es en el objeto -sobre el escandaloso escorzo desnudo y decapitado de Gustave Courbet en "El origen del mundo" (1866) $)^{14}$ - donde las miradas penetrantes y obsesivamente voyeurísticas del pintor y del sicoanalista Jacques Lacan buscan fálicamente poseer para desentrañar la enigmática naturaleza del deseo:

Courbet intentó atrapar en el cuadro la causa de su deseo (subyugado por el síndrome), y el cuadro, a su vez, se convirtió en la imagen del deseo de Lacan, que contrajo el síndrome, y ahora él, Javier, iba a intentar fotografiar (era otro cuadro) la imagen de Nora [...] (132)

La inclusión del cuadro de Courbet en las páginas de la novela sirve, por lo tanto, para plasmar esa búsqueda fallida, compulsiva y retornante dentro de una tradición sociohistórica. En el plano personal, el propio Javier se inscribe en esa tradición desde la niñez al haber acudido, él también, al arte para contemplar, clandestina y solitariamente, a su primer cuerpo femenino. Fue en la casa de su abuelo donde encontró una reproducción de “Los baños turcos” (1862), de Jean-Auguste-Dominique Ingres (1780-1867):

Cuando Javier contempló por primera vez la reproducción en blanco y negro del cuadro de Ingres, nunca había tenido la oportunidad de ver a una mujer desnuda; mucho menos esa confusión de brazos y de piernas, de senos y muslos del cuadro, que sugiere una

${ }_{14}$ Para un estudio detallado sobre la mirada y el voyerisimo en referencia directa a "El origen del mundo" de Courbet ver mi artículo "Las musas inquietantes de Cristina Peri Rossi. Problematización de la mirada masculina en la artes visuales."

Revista Iberoamericana, Vol. LXXVII, Núms. 236-237, Julio-Diciembre 2011, 975-987 ISSN 0034-9631 (Impreso) 
orgía de los sentidos: de la vista y del tacto. Agitado no sabía a cual de ellas mirar primero. [...] Estaba extasiado en la contemplación de los hermosos senos lácteos y redondos, cuando lo sorprendió su abuelo. (152-153)

Es evidente aquí que la repetida mención de los senos y las referencias a su redondez, a los sentidos y a lo lácteo son una manifestación de la fijación infantil del Javier niño con la figura materna. De hecho, el historiador de arte Richard Leppert sugiere lúdicamente que el cuadro debería haberse llamado "Los senos turcos” en vez de "Los baños turcos”, puesto que el pintor claramente inscribe en la pintura su propia fijación con esa parte de la fisiología femenina:

\begin{abstract}
Indeed, the painting might aptly be named “Turkish Breasts” so fixated is Ingres in this physiological feature. The desire to fondle them is prominently displaced from his own fantasy onto the young women at the right who firmly grasps her companion's breast [...] they are for the most part impossible oedipal conflations of maternal nurture and sexual allure_-as it were, breasts for nursing and fondling. (107-8)
\end{abstract}

El cuadro de Ingres nos remite al desnudo de Courbet, puesto que en ambos se inscribe el voyeurismo de la mirada masculina. Si bien el cuadro de Courbet fue escondido detrás de una cortina por Jacques Lacan para la mirada masculina clandestina; en "Los baños turcos" la forma misma de la pintura es circular como si se tratara de una imagen que se observa, a escondidas, por detrás de una mirilla. Tampoco resulta sorprendente el rechazo experimentado por Javier ante la contemplación del escorzo de Tamara Lempicka, la única mujer artista inscrita en la novela, conocida por su bisexualidad y sus "escandalosas" relaciones con otras mujeres: ${ }^{15}$ "En cuanto al Desnudo de Tamara de Lempicka, era violento y brutal. Era muy difícil explicar el carácter brutal de esos retratos. Las líneas eran rígidas, no había sinuosidades. Y donde no hay sinuosidad no hay sensualidad" (Amor 151). Sus desnudos cubistas no son acogedores y mantienen una distancia con el contemplador. Habitan, parafraseando a Leppert, un mundo urbano moderno, de contornos afilados y duros, un mundo poco acogedor donde pareciera que los cuerpos hubieran sido creados en el tiempo de las máquinas (101-2). Carecen por lo tanto de la voluptuosidad suave y láctea de la figura femenina materna en Ingres que acoge, nutre y contiene.

Por otro lado, el hecho de que el escorzo en Lempicka no sea el resultado de la mirada o la mano masculina, sino de la femenina, necesariamente tiene sus implicaciones para el voyeur masculino, en este caso Javier. Margaret Persin indica que el cuerpo femenino creado por la mirada de una artista es, innegablemente, ideológico. Es decir,

15 Similarmente, la única obra de arte, entre las 50, creada por una mujer en la colección de poemas Las musas inquietantes es "Las mutantes” de la también escandalosa pintora argentina Leonor Fini.

$\begin{array}{lllll}\text { ISSN 0034-9631 (Impreso) } & \text { Revista Iberoamericana, Vol. LXXVII, Núms. 236-237, Julio-Diciembre 2011, 975-987 }\end{array}$ 
hace referencia al mundo objetivo, a los códigos de representación subyacentes y a su posición como mujer y como artista dentro de ese mundo y dentro de ese código (Persin 148). Aquí, el efecto de palimpsesto alcanza un plano de complejidad todavía más lúdica, puesto que Peri Rossi lee un texto masculino (Javier) que lee un texto femenino (el Desnudo) creado por una artista femenina (Lempicka) que interpreta el cuerpo femenino, con el agregado de que en estas lecturas se superponen también las diferentes capas de preferencia sexual. Tampoco es de sorprender que el "Desnudo" de Lempicka le recuerde a Javier a Nora, puesto que dicha asociación se da precisamente después de que Nora, vestida, en un intercambio sexual entre ellos, se apropia de su cámara, y por ende del papel de voyeur, para fotografiar el miembro de Javier (Amor 151).

En la novela, por lo tanto, la figura de la madre -ausente-es convocada para la mirada masculina por medio de la contemplación extasiada de la figura femenina plasmada en el arte (los desnudos) o por la contemplación horrorizada de los cuadros de naufragios en los que se inscriben la ausencia y la soledad. Sin embargo, el agua también puede convocar un espacio de plenitud para la mirada masculina. Hay dos instancias concretas en la novela en donde esto ocurre. La primera instancia es durante la contemplación extasiada de otro objeto de arte, u objet trouve ${ }^{16}$ un juego de agua que Javier, a los diez años, descubre en la estantería de un anticuario. El efecto de la contemplación produce una suerte de fascinación hipnótica que detiene momentáneamente el paso del tiempo: "Quedó suspendido, casi ingrávido. Su mente se despojó de todo pensamiento, de toda inquietud: se fusionó con el cilindro de vidrio, se integró al él. Qué satisfacción dejar de ser. Qué plenitud la unión indivisible con el objeto” (Amor 105).

Si bien jamás llega a tocar o tener en sus manos el objeto, la unión que describe se da a través de la mirada que, atravesando el transparente cristal de la vidriera, funciona como un cordón umbilical que vincula al objeto con el sujeto y, por lo tanto, a Javier con el juego de aguas. Posteriormente, la ausencia inevitable del juego de aguas en el anticuario producirá en Javier una angustia existencial. Esta angustia-signo de su soledad y de la dolorosa e irremediablemente reprimida separación de la madre-se manifestará, de forma velada, en la selección del objeto de deseo y surgirá enigmáticamente en la contemplación extasiada de las imágenes, en el establecimiento de sus dependencias o adicciones, en sus sueños o pesadillas y en sus oscuras revelaciones. ${ }^{17}$

La segunda y última instancia donde se textualiza el agua en un objeto de arte será al final de la novela. Una vez concluido el viaje transformativo de un Javier marcado por el cambio en su relación con Nora y por su renuncia a la penetración fálica y al

${ }^{16}$ Aquí concebimos el juego de aguas como objet trouvé puesto que no es inicialmente un objeto de arte pero se convierte en ello por el significado que le atribuye su contemplador -en este caso Javier.

17 Otra expresión de la soledad de Javier que intenta subsanar con el establecimiento de nuevas dependencias es su reacción ante el atardecer o "la hora del lobo". De nuevo el sentimiento de extrema desolación viene de las profundidades de un pasado anterior a la cultura (Amor 87).

ISSN 0034-9631 (Impreso) 
deseo de poseer, él se entregará, transustanciado por completo, a ella y a otra mujer en un intercambio sexual que incluye a los tres, pero donde él cede su posición de poder. Esa noche al regresar al hotel Javier sufre un colapso y al despertarse en el hospital su mirada se detiene en otra pintura marina. En este caso se trata de una reproducción del cuadro "El mar” (1961-1970), del pintor realista español Antonio López (1936). A diferencia del cuadro de Friedrich donde la profundidad oscura del mar lo atraía, lo capturaba vertiginosamente dentro del torbellino del abismo, esta representación del mar le resulta completamente tranquilizadora:

Ese mar de líneas azules, celestes y verdes no era tampoco, la profundidad del mar. La otra cosa que era le producía una gran serenidad, lo acogía, lo contenía. Podía descansar tranquilamente; podía dormitar, porque sabía que, al despertarse, sus ojos se encontrarían con la calma, la quietud bienhechora de esas aguas que no eran agua, sino otra cosa. “El líquido amniótico”, pensó Javier. (236)

Desde una nueva perspectiva brindada por la constatación de la naturaleza lúdica de los sistemas representacionales y desde el conocimiento de que la clave al enigma del deseo está en él, en tanto sujeto deseante, Javier deja de interrogar. Como la pipa que una vez dibujada perfectamente por Magritte deja de ser una pipa -de carne y hueso, por así decirlo- para convertirse simplemente en una representación artística; “ El mar” realista de Antonio López y el deseo de Javier remiten, necesariamente siempre, a otra cosa "y esa otra cosa no se podía nombrar, del mismo modo que se dice para no decir, se escribe para no escribir y se representa para no representar" (Amor 235). La novela concluye cuando Javier suspende su búsqueda por descifrar la enigmática naturaleza del objeto de deseo al tomar, finalmente, conciencia de que los objetos en sí -las imágenes de la amada, las obras de arte- carecen de significación propia. Su valor y el efecto que producen -fascinación, éxtasis, parálisis, miedo, horror-, irrumpen, de forma velada, desde la subjetividad por medio de la mirada.

\section{BiBLIOGRAFÍA}

Bergmann, Emilie L. Art Inscribed: Essays on Ekphrasis in Spanish Golden Age Poetry. Cambridge: Harvard UP, 1979.

Dejbord-Sawan, Parizad. “Las musas inquietantes deCristina Peri Rossi. Problematización de la mirada masculina en las artes visuales”. Romance Notes 46/3 (2007).

"Prácticas visuales revisionistas o la recuperación del cuerpo femenino en tres poemas -“La encajera”, "La lección de guitarra” y "El origen del mundo"- de Cristina Peri Rossi”. Chasqui 36/1 (2007).

Freud, Sigmund. The Uncanny. David MacLintock, trad. Nueva York: Penguin, 2003.

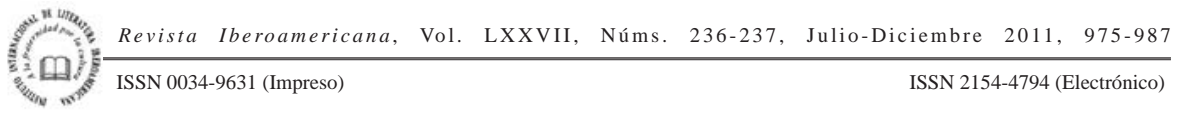


Leppert, Richard. The Nude. The Cultural Rhetoric of the Body in the Art of Western Modernity. Boulder: Westview, 2007.

Magherini, Graziella. El síndrome de Stendhal. Madrid: Espasa Calpe, 1990.

Mangieri, Rocco. "Parálisis, trauma y crisis en la experiencia estética: el síndrome de Stendhal”. Tonos Digital 15. (junio 2008). <http://www.tonos digital.com/ojs/index. php/tonos/article/viewArticle/204/106>. 5 enero 2011.

McNally, Terence. The Stendhal Syndrome: Full Frontal Nudity and Prelude \& Liebestod. Nueva York: Grove, 2004.

Peri Rossi, Cristina. Solitario de amor. Barcelona: Grijalbo, 1988. Fantasías eróticas. Madrid: Temas de Hoy, Colección Biblioteca Erótica, 1991. Las musas inquietantes. Barcelona: Lumen 1999.

El amor es una droga dura. Barcelona: Seix Barral, 1999.

Persin, Margaret H. Getting the Picture. The Ekphrastic Principle in Twentieth-Century Spanish Poetry. Londres: Associated UP, 1997.

Saona, Margarita. "La masculinidad en crisis: El amor es una droga dura de Cristina Peri Rossi”. Espéculo: Revista de Estudios Literarios 35. 3 mayo 2007. <http:// www.ucm.es/info/especulo/numero35/crimascu.html>. 5 enero 2011.

Revista Iberoamericana, Vol. LXXVII, Núms. 236-237, Julio-Diciembre 2011,975-987 
